\title{
Prevention in child and adolescent psychiatry: are we there yet?
}

\author{
Carmen Moreno ${ }^{1}$
}

Published online: 13 February 2017

(C) Springer-Verlag Berlin Heidelberg 2017

Neuropsychiatric disorders accounts for almost half of causes of disability in adolescents and young adults [1], an age group traditionally perceived as healthy. Although development and implementation of preventive strategies in child psychiatry is still rare, a growing field of research is exploring environmental risk factors that could be useful for developing preventive interventions. In this number, Pickles et al. [2], studying a large representative population sample of first-time mothers, report on moderator effects of maternal stroking in the relationship between pregnancyspecific anxiety and internalising and externalising symptoms in children. They report that high levels of infant stroking at 9 weeks of age had enduring effects on reducing the strength of association between maternal anxiety, a known index of prenatal stress, and ratings of internalising, externalising, and aggressive behaviour in children aged 3.5 years. The authors propose that maternal behaviour could modify the expression of glucocorticoid receptors, reversing the foetal programming effects of stress. Also in this issue, results from another large population-based birth cohort support mediation effects of maternal behaviour on child psychopathology [3]. Smarius et al. found that excessive infant crying postnatally correlated with a twofold increase in behaviour and mood problems at 5-6 years, an association mediated in their sample by maternal burden of infant care and maternal behaviour. Therapeutic implications of these findings merit further exploration.

Carmen Moreno

cmoreno@hggm.es

1 Child and Adolescent Psychiatry Department, Hospital General Universitario Gregorio Marañón, School of Medicine, Universidad Complutense, IiSGM, CIBERSAM, Madrid, Spain
Promoting mental health in general requires promoting mental health in children and adolescents. There is no disagreement that most psychiatric illnesses are neurodevelopmental conditions whose first symptoms appear before adult age [4]. Highly prevalent but preventable risk factors are also common at early ages. Child maltreatment may be a good example. A 2013 report of the WHO regional office for Europe on child maltreatment estimates that, in Europe, 18 million children suffer from sexual abuse, 44 million from physical abuse and 55 million from mental abuse [5]. Child maltreatment has been claimed as the preventable cause for all childhood psychiatric conditions with the highest associated disease burden. It may account for about $20 \%$ of population-attributable risk, separately from other behavioural or physical consequences of abuse (risky health behaviours, obesity or other non-communicable diseases) with their own psychiatric outcomes [6]. Reducing child maltreatment is no longer the exclusive domain of child protection services. It is a public health goal required by Health 2020, the European health policy framework [5]. Social crises, such as the current refugee crisis, also have more profound impacts on children and adolescents, making initiatives such as the ESCAP project for mental health of child and adolescents refugees especially relevant.

We also know that some populations may be more vulnerable than others to the effects of environmental stressors. In a gene $\mathrm{x}$ environment interaction investigation on the effect of institutional care quality on ADHD symptoms also in this issue, Baptista et al. report that negative outcomes of intrusive caregiving are moderated by the serotonin transporter polymorphism, with a direct relationship between ADHD symptoms and intrusive caregiving in $\mathrm{s} / \mathrm{s}$ homozygotes [7]. Identifying patient subgroups more amenable to specific interventions has been a fruitful strategy in other areas of medicine. Stratification based 
on the molecular makeup of tumours, now widely implemented, has improved survival rates of oncologic diseases. Future research on neurodevelopmental conditions such as autism spectrum disorders or early onset psychotic disorders should follow a similar approach, identifying potential novel treatments based on growing insights into the relevant biological pathways [8]. The timing of the interventions is also important, as particular risk factors are especially deleterious at sensitive periods during development [9]. Thus, interventions during sensitive developmental periods are likely to be more effective. Perinatal phosphatidylcholine and vitamin D supplementation have shown efficacy as preventive strategies $[10,11]$. This is true not only for biological treatments but for interventions targeting environmental stressors. For instance, the especially durable psychiatric and social effects of bullying during late childhood and early adolescence may be related to the central role of acceptance by peers in the development of individual and group identity during this period [12].

While prevention in psychiatry should lean on primary prevention and mental health promotion, there is still a lot of room for improvement on lifetime mental health and disability via implementation of secondary and tertiary preventive strategies at early ages. Duration of psychiatric disorders in children and adolescents is one of the main predictors of mental disorders in adulthood [13], which highlights the role of early intervention on mental health promotion across ages. EMA regulations now legally oblige companies seeking approval of adult-use medication to also study the medications' performance in children. Yet there are still few treatment options for paediatric psychiatric disorders. Autism, intellectual disability, conduct disorders and severe affective disorders have all been identified as priority areas in need of treatment research [8]. The EMA has launched the European Network of Paediatric Research (Enpr-EMA), to facilitate studies and increase the availability of authorised paediatric treatments (http://www.ema. europa.eu/ema/index.jsp?curl=pages/partners_and_networks/general/general_content_000303.jsp). Within child and adolescent psychiatry, expert collaboration on developing paediatric investigation plans, harmonisation of clinically relevant outcomes, standards and processes, as well as developing a network of centres of excellence for conducting clinical trials in European settings may help overcome current doubts about the relevance and generalisability of paediatric clinical trial results. Collaborative research, as depicted in articles in this issue [14, 15], is especially relevant in paediatric psychiatric studies, to increase the number of studies and promote the generalisation of their findings.

In addition to the lack of enough high-quality evidence for treatments, the reality of clinical settings is widely heterogeneous. In Europe, efficacious interventions for prevalent disorders such as some stimulants or electroconvulsive therapy may not be available depending on the country, while other non-evidence-based treatments are available and covered by national health services. We still need effective treatments for children and adolescents with psychiatric disorders, effective dissemination strategies of known evidence-based treatments, and research-based policies on treatment availability. Although many research funders neglect neurodevelopmental psychiatry, some initiatives at the European level, such as the recently launched Innovative Medicines Initiative 2 (IMI 2) that includes such topics as the Creation of a pan-European paediatric clinical trials network and Personalised medicine approaches in autism spectrum disorders, are starting to focus on early ages. Let us hope that there are more to come and that soon they will be the rule rather than the exception.

Acknowledgements Supported by the Spanish Ministry of Economy, Industry and Competitiveness. Instituto de Salud Carlos III, cofinanced by ERDF Funds from the European Commission, "A way of making Europe", CIBERSAM. Madrid Regional Government (S2010/ BMD-2422 AGES), European Union Structural Funds and European Union Seventh Framework Program; Fundación Alicia Koplowitz and Fundación Mutua Madrileña.

\section{Compliance with ethical standards}

Conflict of interest Dr. Moreno has been a consultant for Janssen, Servier, and Lundbeck.

\section{References}

1. Gore FM, Bloem PJ, Patton GC, Ferguson J, Joseph V, Coffey C, Sawyer SM, Mathers CD (2011) Global burden of disease in young people aged 10-24 years: a systematic analysis. Lancet 377(9783):2093-2102. doi:10.1016/S0140-6736(11)60512-6

2. Pickles A, Sharp H, Hellier J, Hill J (2017) Prenatal anxiety, maternal stroking in infancy, and symptoms of emotional and behavioral disorders at 3.5 years. Eur Child Adolesc Psychiatry. doi:10.1007/s00787-016-0886-6

3. Smarius LJCA, Strieder TGA, Loomans EM, Doreleijers TAH, Vrijkotte TGM, Gemke RJ, van Eijsden M (2017) Excessive infant crying doubles the risk of mood and behavioral problems at age 5: evidence for mediation by maternal characteristics. Eur Child Adolesc Psychiatry. doi:10.1007/s00787-016-0888-4

4. Sommer IE, Bearden CE, van Dellen E, Breetvelt EJ, Duijff SN, Maijer K, van Amelsvoort T, de Haan L, Gur RE, Arango C, Díaz-Caneja CM, Vinkers CH, Vorstman JA (2016) Early interventions in risk groups for schizophrenia: what are we waiting for? NPJ Schizophr 2:16003. doi:10.1038/npjschz.2016.3 (eCollection 2016)

5. http://www.euro.who.int/__data/assets/pdf_file/0019/217018/ European-Report-on-Preventing-Child-Maltreatment.pdf. Accesed Feb 2017

6. Constantino JN (2016) Child maltreatment prevention and the scope of child and adolescent psychiatry. Child Adolesc Psychiatr Clin N Am 2:157-165. doi:10.1016/j.chc.2015.11.003 (review) 
7. Baptista J, Belsky J, Mesquita A, Soares I (2017) Serotonin transporter polymorphism moderates the effects of caregiver intrusiveness on ADHD symptoms among institutionalized preschoolers. Eur Child Adolesc Psychiatry. doi:10.1007/ s00787-016-0890-x

8. Persico AM, Arango C, Buitelaar JK, Correll CU, Glennon JC, Hoekstra PJ, Moreno C, Vitiello B, Vorstman J, Zuddas A, Child European, Network Adolescent Clinical Psychopharmacology (2015) Unmet needs in paediatric psychopharmacology: present scenario and future perspectives. Eur Neuropsychopharmacol 10:1513-1531. doi:10.1016/j.euroneuro.2015.06.009 (review)

9. Parellada M (2013) Why psychogeriatrics starts right after adolescence. Eur Child Adolesc Psychiatry 7:391-393. doi:10.1007/ s00787-013-0434-6

10. Ross RG, Hunter SK, Hoffman MC, McCarthy L, Chambers BM, Law AJ, Leonard S, Zerbe GO, Freedman R (2016) Perinatal phosphatidylcholine supplementation and early childhood behavior problems: evidence for CHRNA7 moderation. Am J Psychiatry 5:509-516. doi:10.1176/appi.ajp.2015.15091188

11. Vinkhuyzen AA, Eyles DW, Burne TH, Blanken LM, Kruithof CJ, Verhulst F, Jaddoe VW, Tiemeier H, McGrath JJ (2016) Gestational vitamin D deficiency and autism-related traits: the Generation R Study. Mol Psychiatry. doi:10.1038/mp.2016.213
12. Takizawa R, Maughan B, Arseneault L (2014) Adult health outcomes of childhood bullying victimization: evidence from a fivedecade longitudinal British birth cohort. Am J Psychiatry 7:777784. doi:10.1176/appi.ajp.2014.13101401

13. Patton GC, Coffey C, Romaniuk H, Mackinnon A, Carlin JB, Degenhardt L, Olsson CA, Moran P (2014) The prognosis of common mental disorders in adolescents: a 14-year prospective cohort study. Lancet 383(9926):1404-1411. doi:10.1016/ S0140-6736(13)62116-9

14. Højgaard DRMA, Mortensen EL, Ivarsson T, Hybel K, Skarphedinsson G, Nissen JB, Valderhaug R, Dahl K, Weidle B, Torp NC, Grados M, Lewin AB, Melin KH, Storch EA, Wolters LH, Murphy TK, Sonuga-Barke EJS, Thomsen PH (2017) Structure and clinical correlates of obsessive-compulsive symptoms in a large sample of children and adolescents: a factor analytic study across five nations. Eur Child Adolesc Psychiatry. doi:10.1007/ s00787-016-0887-5

15. Koenig J, Brunner R, Fischer-Waldschmidt G, Parzer Plener PL, Park J, Wasserman C, Carli V, Hoven CM, Sarchiapone Wasserman D, Resch F, Kaess M (2017) Prospective risk for suicidal thoughts and behaviour in adolescents with onset, maintenance or cessation of direct self-injurious behaviour. Eur Child Adolesc Psychiatry. doi:10.1007/s00787-016-0896-4 